\begin{tabular}{|c|c|c|}
\hline J & $\begin{array}{l}\text { International Journal of Current Research in } \\
\text { Biosciences and Plant Biology }\end{array}$ & $y=$ \\
\hline & Volume $7 \bullet$ Number 9 (September-2020) • ISSN: 2349-8080 (Online) & \\
\hline $\begin{array}{l}\text { EXCELLENT } \\
\text { PUBLISHERS }\end{array}$ & Journal homepage: $\underline{w w w . i j c r b p . c o m}$ & \\
\hline
\end{tabular}

\title{
Antimicrobial, anti-biofilm and anti-quorum sensing compounds from the bark of Ekebergia capensis
}

\author{
Abu F. Meka1, Yadessa M. Ayana² and Teshome G. Biru1* \\ ${ }^{1}$ Department of Biology, Natural and Computational Science College, Bule Hora University, \\ P.O. Box 144, Bule Hora, Ethiopia \\ ${ }^{2}$ Department of Applied Chemistry, School of Applied Natural Science, Adama Science and Technology University, \\ P.O. Box 1888, Adama, Ethiopia \\ 3Department of Applied Biology, School of Applied Natural Science, Adama Science and Technology University, \\ P.O. Box 1888, Adama, Ethiopia \\ *Corresponding author; e-mail: teshome.geremew@gmail.com
}

\begin{tabular}{|c|c|}
\hline Article Info & ABSTRACT \\
\hline $\begin{array}{l}\text { Date of Publication: } \\
\text { o6 September } 2020\end{array}$ & \multirow{3}{*}{$\begin{array}{l}\text { The main objective of this study was to isolate bioactive compounds from Ekebergia } \\
\text { capensis for antimicrobial, anti-biofilm and anti-quorum sensing activity. The bark of } \\
\text { E. capensis was extracted using hexane, ethyl acetate and methanol for } 72 \text { hours on } \\
\text { maceration at room temperature. Antibacterial activity was evaluated against } \\
\text { Staphylococcus aureus and antifungal activity against Candida albicans at } 5 \text { and } 10 \\
\text { mg/mL concentrations. Anti-biofilm activity was tested using test tube and swarming } \\
\text { motility test methods and anti-quorum sensing was evaluated using flask incubation } \\
\text { test for violacein inhibition production methods. The results showed ethyl acetate } \\
\text { extract of } E \text {. capensis and its two isolated compounds exhibited antimicrobial, anti- } \\
\text { biofilm and anti-quorum sensing activity. Inhibition zones of antimicrobial activities of } \\
\text { the extract against } S \text {. aureus and } C \text {. albicans ranged between } 4-20 \text { mm. } 10 \mathrm{mg} / \mathrm{mL} \\
\text { extract showed inhibition of biofilm formation against } S \text {. aureus, anti-swarming } \\
\text { activities against } P \text {. aeruginosa and } S \text {. aureus. Inhibition of violacein production } \\
\text { against } S \text {. aureus, P. aeruginosa, and } C \text {. albicans were } 72.6 \%, 67.7 \% \text { and } 69.3 \% \\
\text { respectively. The ethyl acetate extract, which showed antimicrobials, anti-biofilm, anti- } \\
\text { quorum sensing activities, after silica gel column chromatography furnished two } \\
\text { compounds namely; diisobutylphtalate and Sandropin B. The chemical structures of } \\
\text { these compounds were done using spectroscopic methods including IR and NMR. The } \\
\text { isolated compounds also showed strong antimicrobial, anti-biofilm, and anti-quorum } \\
\text { sensing activity. This could be useful to manage infectious diseases caused by biofilm } \\
\text { forming microorganisms. }\end{array}$} \\
\hline Keywords & \\
\hline $\begin{array}{l}\text { Antimicrobials } \\
\text { Biofilm } \\
\text { Ekebergia capen } \\
\text { Extraction } \\
\text { Microorganisms } \\
\text { Quorum sensing }\end{array}$ & \\
\hline
\end{tabular}

\section{Introduction}

The discoveries of new antimicrobial agents are providing effective control of large number of lives treating infectious diseases (Ling et al., 2015).
Although multidrug resistance bacteria have been increased because of microbial resistance, antibiotic treatments became more challenging to produce and clinically implement. Recent researches documented antibiotic resistance needs 
for the development of different target process in the pathogen including quorum sensing and biofilm formation (Tanver et al., 2017; Tang et al., 2019). Quorum sensing consists of cell-to cell communication that depends on the production and response to small diffusible molecule called auto-inducers. This can lead to the formation of biofilm and causing other virulence factors which are problems for food safety and biofilm related infectious diseases (Tanver et al., 2017).

Considering the impact of quorum sensing and biofilm, several strategies including cleaning agent, phages, irradiation, and essentials oil have been developed in food factory and drug discovery (Tanver et al., 2017; Liu et al., 2020). Preventing spoilage of food and bacterial infection by using medicinal plants is safe and non-toxic regarding to health status. Further, blocking of quorum sensing signal transduction can be achieved by using an antagonist molecule capable of competing or interfering with the native Acyl-Homoserine Lactone (AHL) signal for binding to the LuxR (auto inducer responsive transcriptional activator) type receptor (Koh et al., 2013).

Competitive inhibitors are structurally like the native AHL signal and can bind to and occupy the AHL-binding site but will fail to activate the LuxRtype receptor. The noncompetitive inhibitors show little or no structural similarity to AHL signals and these molecules bind to different sites on the receptor protein (Koh et al., 2013). Thus, quorum sensing inhibitors that can either target synthesis of the cell signaling molecules or block these signaling systems can be used to prevent spoilage of food and biofilm formation by food-related bacteria (Tanver et al., 2017).

Biofilm, microbial cell factory, is a community of microorganisms in which microbial cells attach to each other on a living or non-living surface within a self-produced matrix of extracellular polymeric substance (Bueno, 2014). Biofilms are fixed in a matrix which contains polysaccharides, proteins, and extracellular microbial DNA. Because it provides a reservoir for microbial cells, its dispersion increases the risk of chronic and persistent infections. It may also promote the reinfection of colonized sites (Berlanga and Guerrero, 2016). Similarly, the matrix confers a protection against biocides and drugs and has environmental promoters that induce biofilm formation and contributes to drug resistance development (Tan et al., 2014).

Several investigators recently reported the antimicrobial activity of plant derived essential oils, secondary metabolites of plant origin and biofabricated silver nanoparticles (Bereksi et al., 2018; Mishra et al., 2020; Tamfu et al., 2020). Their application as food preservatives to control food spoilage and food borne pathogenic bacteria is due to their growth inhibition property (Tanver et al., 2017). In Ethiopia, local people use different medicinal plants to preserve food, treat infectious diseases, and as a source of foods.These plants were collected from wild habitats and prepared either in dry form or fresh form remedies. Most of the remedy preparations did not have additive while some have different additive like honey, sugar, butter and oil for the treatment of single ailment (information gathered from traditionally healer peoples or folk medicine). Based on the traditional use of the medicinal plants, this study tried to isolate bioactive compounds from bark of E. capensis for anti-biofilm, anti-quorum sensing and antimicrobial properties.

\section{Materials and methods}

\section{Collection of experimental plants}

The bark of $E$. capensis (1 Kg) was collected from Oromia Region, North Shewa, Kuyu Woreda. Kuyu Woreda is located at latitude and longitude of $9^{\circ} 50^{\prime} \mathrm{O}^{\prime} \mathrm{N} 38^{\circ} 20^{\prime} \mathrm{O}^{\prime} \mathrm{E}$ and an elevation between 2515 and 2547 meters above sea level. Fresh sample were collected, packed in plastic bags and transported into the laboratory. The plant materials were authenticated by a botanist at Addis Ababa University Biology Department and voucher specimens (MG-03/05) were stored.

\section{Preparation of plant extract}

The sequential extraction method described by Ncube et al. (2008) was applied with slight modifications as follows. Briefly, the bark of $E$. capensis were washed thoroughly under running tap water, dried under shade at room temperature for 15 days and powdered manually with metal mortar and pestle to facilitate the extraction process. The finely ground plant material (273 g) 
was soaked in $1.5 \mathrm{~L}$ of hexane for 72 hours with occasional swirling to ensure thorough extraction. The soaked materials were filtered, concentrated using rotary evaporator and dried and weighed. After extraction with hexane, the same procedure was repeated with ethyl acetate and methanol. The extracts were stored in the refrigerator at $4^{\circ} \mathrm{C}$ until further analysis.

\section{Test organisms}

Two reference strains of human pathogenic bacteria representing Gram-positive ( $S$. aureus ATCC 6538) and Gram-negative ( $P$. aeruginosa ATCC 9027) bacteria and a pathogenic fungus $(C$. albicans ATTCC 64550) obtained from Ethiopian Institute of Biodiversity were used through this study.

\section{Antimicrobial susceptibility test}

The antimicrobial activity of the crude extracts of experimental plants against Gram-positive ( $S$. aureus) and Gram-negative bacteria ( $P$. aeruginosa) and a Fungus (C. albicans) was carried out by disk diffusion method. Mueller Hinton Agar (MHA) and Sabouraud Dextrose Agar (SDA) were prepared for each organism as follows. $20 \mathrm{~mL}$ of sterile MHA and SDA poured into sterilized Petri dishes separately and set aside. After solidifying, about $5 \times 10^{8}$ cells ( 0.5 McFarland standard) of test organisms of bacteria and fungi were spread on MHA and fungus were spread on SDA. Sterilized filter paper discs ( $6 \mathrm{~mm}$ diameter) were loaded with various concentrations of the extract, air dried and placed onto the surface of the agar plate at equal distance from each other as described by (Clutterbuck et al., 2007). Gentamycin sulfate $(1 \mu \mathrm{g} / \mathrm{mL})$ and Nystatin (1 $\mu \mathrm{g} / \mathrm{mL}$ ) were used as positive controls for bacterial cultures and Candida albicans respectively.

Each disc was pressed down to ensure complete contact with the agar surface and the discs were placed with a dispensing apparatus. The plates were inverted and incubated at $37^{\circ} \mathrm{C}$ for 24 hours for bacteria and $48 \mathrm{hrs}$ at $25^{\circ} \mathrm{C}$ for Candida albicans. The antimicrobials susceptibility was evaluated by measuring zones of inhibition from triplicate experiments and the results were reported as mean $\pm \mathrm{SD}$.

\section{Anti-biofilm activity test}

\section{Test tube method}

Test organisms $(100 \mu \mathrm{L})$ containing about $5 \times 10^{8}$ $\mathrm{CFU} / \mathrm{mL}$ were transferred to test tubes containing $10 \mathrm{~mL}$ Luria Bertani (LB). $100 \mu \mathrm{L}$ solution containing 5 and $10 \mathrm{mg} / \mathrm{ml}$ of crude extract of bark of $E$. capensis were added separately to the test tubes containing the test organisms and incubated at $37^{\circ} \mathrm{C}$ for 72 hours. The medium was removed and the tubes were washed with distilled water, air dried and biofilm formation in the tubes was tested using crystal violet. All tests were carried out in triplicates and results of the test were recorded as mean \pm SD.

\section{Swarming motility test}

Swarm plates were prepared using nutrient agar containing $0.5 \%$ peptone, $0.2 \%$ yeast extract and $1.0 \%$ glucose per $100 \mathrm{ml}$ of distilled water. $250 \mu \mathrm{l}$ of plant extracts were added to $10 \mathrm{~mL}$ semisolid agar, gently mixed and poured immediately onto the surface of a 10mL of pre-warmed agar plate as an overlay. Twenty microliters of standardized inoculums $\left(5 \times 10^{8}\right)$ of $P$. aeruginosa, and $S$. aureus were placed on the center of the plate. Similar volume of test organisms were placed on the center of plates as negative control and overlaid with agar alone. The plates were incubated for overnight at $37^{\circ} \mathrm{C}$ upright position for 30 hours.

\section{Anti-quorum sensing activity test}

Flask incubation test for quantification of violacein production: $2 \mu \mathrm{L}$ of test organisms were inoculated in Erlenmeyer flasks containing $20 \mathrm{~mL}$ of $\mathrm{LB}$ supplemented with 5 and $10 \mathrm{mg} / \mathrm{mL}$ extract of $E$. capensis. The flasks were incubated at $37^{\circ} \mathrm{C}$ in a shaking incubator for $30 \mathrm{oh}$. $2 \mathrm{~mL}$ of each culture were transferred to test tube and centrifuged at $1500 \mathrm{rpm}$ for 15 minutes to precipitate the insoluble pigment. The pellet was re-suspended in $2 \mathrm{~mL}$ of dimethyl sulfoxide (DMSO) and homogenized by vortexing. Violacein absorbance at $585 \mathrm{~nm}$ was determined using UV-visible spectrophotometer. The negative control test without the extract was also evaluated for violacein absorbance. Inhibition was calculated using the following formula with respect to the control from triplicate measurements. 


$$
\text { Inhibition of violacein production }=\frac{\mathrm{Ac}-\mathrm{As}}{\mathrm{Ac}} \times 100
$$

Ac $=$ Absorbance of control, As = Absorbance of sample.

\section{Isolation of bioactive compounds}

\section{Column chromatography}

The most active ethyl acetate extract of $E$. capensis was subjected to silica gel column chromatography. Briefly, silica gel (130 g) was mixed with $200 \mathrm{~mL}$ of n-hexane to form a homogenous suspension/slurry and stirred using a glass-stirring rod to remove bubbles. The silica gel slurry was then poured into a glass column. The EtOAc extract $(2.5 \mathrm{~g})$ was adsorbed on equal amount of silica gel and subjected to column chromatography using hexane: EtOAc: $\mathrm{MeOH}$ of increasing polarities as eluent to give 80 fractions. The column was first eluted with n-hexane as the mobile phase with the polarity increasing by $5 \%$ increments of ethyl acetate. The fraction eluted with n-hexane: EtOAc (70:30) furnished compound 1 while the second compound was eluted with n-hexane: EtOAc (60:40).

\section{Structure elucidation of the bioactive compounds}

Analytical thin layer chromatograms were run on a readymade $0.2 \mathrm{~mm}$ thick layer of silica gel GF254
(Merck) coated on aluminium plate. Column chromatography was performed using silica gel (230-400 mesh) Merck. ${ }^{1} \mathrm{H}-,{ }^{13} \mathrm{C}-$ and DEPT-NMR spectra were recorded on a Bruker advance 400 spectrometer operating at $400 \mathrm{MHz}$ in $\mathrm{CDCl}_{3}$ and DMSO- $\mathrm{d}_{6}$. All chemical shifts were stated in parts per million (ppm) and coupling constants were expressed in Hz. Infrared (IR) spectra were obtained on Perkin-Elmer 65FT (IR $v_{\max } \mathrm{KBr}$ (4000-400) $\mathrm{cm}^{-1}$ ) infrared spectrometer using $\mathrm{KBr}$ pellets.

\section{Data analysis}

The data was analysed using Minitab (Version 17) software and Excel. The differences between test groups and control groups were analysed by oneway and two-way analysis of variance (ANOVA) and the results were presented using tables and graphs. A p-value of less than 0.05 was considered statistically significant at $95 \%$ level of confidence.

\section{Results}

\section{Antimicrobials activity of extracts}

The results obtained in this study showed that ethyl acetate extracts of $E$. capensis displayed antibacterial activity on $S$. aureus and antifungal activity on $C$. albicans at $10 \mathrm{mg} / \mathrm{mL}$ concentrations. E. capensis crude extract inhibit the growth of $S$. aureus, $C$. albicans but did not inhibit growth of $P$. aeruginosa (Table 1 ).

Table 1. Effect of crude extract of E. capensis at $10 \mathrm{mg} / \mathrm{mL}$ against $S$. aureus, P. aeruginosa, C. albicans.

\begin{tabular}{llll}
\hline \multirow{2}{*}{ Extraction solvent } & \multicolumn{2}{l}{ Zone of inhibition in mm } & C.albicans \\
\cline { 2 - 4 } & S. aureus & P. aeruginosa & $20 \pm 1.98$ \\
Ethyl acetate & $16 \pm 1.5$ & NI & $6.5 \pm 0.34$ \\
n-hexane & NI & NI & $4 \pm 0.67$ \\
Methanol & $6 \pm 1.22$ & $22 \pm 1.6$ & NT \\
Gentamycin sulfate & $20 \pm 1.33$ & NT & $25 \pm 0.66$ \\
Nystatin & NT &
\end{tabular}

The ethyl acetate extract of E. capensis showed highest degrees of antibacterial $(16 \mathrm{~mm})$ and antifungal $(20 \mathrm{~mm})$ activities. The largest zone of inhibition was observed (20mm) against $C$. albicans followed by $(16 \mathrm{~mm})$ against $S$. aureus. Hexane extract did not show any antibacterial and antifungal activity towards the selected test organisms.

\section{Anti-biofilm activity test}

The observations of heavy crystals violate pigment remaining on the test tube implicated biofilm formation by $C$. albicans and $P$. aeruginosa as compared with control counterparts. The biofilm formed by $S$. aurous was not appreciable as compared with $C$. albicans and $P$. aeruginosa. The 
initial cell attachment of $S$. aureus was significantly inhibited by of $E$. capensis extract at the concentration of $10 \mathrm{mg} / \mathrm{mL}$. The crystal violet assay indicated that the effect of $E$. capensis extract on initial cell attachment. Ethyl acetate extract of $E$. capensis at concentration of $10 \mathrm{mg} / \mathrm{ml}$ concentration inhibited biofilm formation of $S$. aureus.

\section{Swarming motility inhibition}

The swarming motility assay on overnight cultures of the test bacteria were point inoculated at the centre of the medium consisting of $1 \%$ tryptone, $0.5 \% \mathrm{NaCl}$ and $0.3 \%$ agar with $10 \mathrm{mg} / \mathrm{ml}$ concentrations of extracts. The plates were incubated at $30{ }^{\circ} \mathrm{C}$ in upright position for $24 \mathrm{~h}$. Following swarm zones of the bacterial cells swarming migration were observed. Ethylacetate extract of E. capensis at 5 and $10 \mathrm{mg} / \mathrm{mL}$ showed significant influence on the swarming motility on different microorganisms. Of the two concentrations tested for anti-swarming activities, $10 \mathrm{mg} / \mathrm{mL}$ extract of E. capensis showed better activity on $P$. aeruginosa and $S$. aureus.

\section{Flask incubation test for inhibition of violacein production}

The inhibitory effect of the $E$. capensis extract against $S$. aureus, and $C$. albicans for violacein pigment production was measured and quantified by spectrophotometers as indicated in Table 2. A concentration of $10 \mathrm{mg} / \mathrm{mL}$ extract inhibited $72.6 \%$ violacein production as compared to $5 \mathrm{mg} / \mathrm{mL}$ concentrations (16.2\%).

Table 2. Inhibition of violacein production by E. capensis extract.

\begin{tabular}{|c|c|c|c|}
\hline \multirow[b]{2}{*}{ Plant species } & \multirow[b]{2}{*}{ Microorganisms } & Concentration mg/ml & \multirow{2}{*}{$\begin{array}{l}\% \text { of inhibition of violacein } \\
\text { production at } 10 \mathrm{mg} / \mathrm{ml}\end{array}$} \\
\hline & & $\begin{array}{l}5 \\
\text { Absorbance at } 585 \mathrm{~nm}\end{array}$ & \\
\hline E. capensis & $\begin{array}{l}\text { P. aeruginosa } \\
\text { S. aureus } \\
\text { C. albicans }\end{array}$ & $\begin{array}{ll}0.55 & 0.20 \\
0.52 & 0.17 \\
0.57 & 0.19\end{array}$ & $\begin{array}{l}67.74 \% \\
72.6 \% \\
69.35 \%\end{array}$ \\
\hline
\end{tabular}

NB: the absorbance of control was 0.62 .

\section{Isolation and characterization of bioactive compounds from $E$. capensis extract}

\section{Compound 1}

Compound 1 was isolated as purple solid melted at $77-78^{\circ} \mathrm{C}$. The infra-red (IR) spectrum of compound 1 showed several intense bands in the region of 4000 and $500 \mathrm{~cm}^{-1}$. The band due to $\mathrm{O}-\mathrm{H}$ stretching is evident at $3445 \mathrm{~cm}^{-1}$, C-H stretching at $2902 \mathrm{~cm}^{-1}$, and carbonyl group $(\mathrm{C}=\mathrm{O})$ at 1710 $\mathrm{cm}^{-1}$. The ${ }^{1} \mathrm{H}-\mathrm{NMR}$ spectrum of compound 1 shows the presence of proton signals in the aliphatic and aromatic region. The signal at $\delta 0.99(12 \mathrm{H}, \mathrm{d})$ is accounted to the presence of four methyl groups in the compound. Also observed is the signal at 2.06 $(2 \mathrm{H}$, sep.) due to the methine proton on carbon bearing two methyl groups. The proton signal on oxygenated carbon is evident at $4.11(4 \mathrm{H}, d, J=7.6$ $\mathrm{Hz})$. The spectrum also showed signals in the aromatic region at $7.75(2 \mathrm{H}, d d, J=9.2$ and 3.6 $\mathrm{Hz})$ and $7.56(2 \mathrm{H}, d d, J=9.2$ and $3.6 \mathrm{~Hz})$. The ${ }^{13} \mathrm{C}-$ NMR spectrum of compound 1 with the aid of DEPT-135 showed the presence of eight carbon resonances of which two quaternaries, three methine, two methyl and one methylene. The carbon signal at $\delta 167.6$ is accounted to the presence of carbonyl carbon of an ester which agrees well with the IR spectrum of the same compound. The three carbon signals in the aromatic region were evident at 132.4, 130.9 and $128.8 \mathrm{ppm}$. The signal due to an oxygenated methylene carbon was observed at $71.8 \mathrm{ppm}$. The ${ }_{13} \mathrm{C}-\mathrm{NMR}$ spectrum of compound 28 also showed signal in the aliphatic region at 27.7 and $19.1 \mathrm{ppm}$ accounted to the presence of methine and methyl groups, respectively. The data generated agrees with the compound whose structure is shown in Fig. 1.

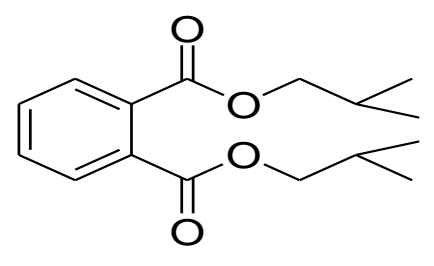

1

Fig. 1: Structure of compound 1 (diisobutylphtalate). 


\section{Compound 2}

Compound 2 was isolated as yellow needle like crystals melted at $209-211^{\circ} \mathrm{C}$. The infra-red (IR) spectrum of compound 2 showed several intense bands in the region of 4000 and $600 \mathrm{~cm}^{-1}$. The band due to hydroxyl $(\mathrm{O}-\mathrm{H})$ stretching is evident at $3497 \mathrm{~cm}^{-1}$. The IR spectrum also showed bands due to carbonyl group $(\mathrm{C}=\mathrm{O})$ at $1741 \mathrm{~cm}^{-1}$ and the band at $3000 \mathrm{~cm}-1$ is accounted to $\mathrm{C}-\mathrm{H}$ stretching of hydrocarbons. The ${ }^{1} \mathrm{H}-\mathrm{NMR}$ spectrum $\left(\mathrm{CDCl}_{3}\right)$ of compound 2 showed signals at $7.52(1 \mathrm{H}), 7.40(1 \mathrm{H})$ and $6.37(1 \mathrm{H})$ accounted to the presence of hydrogens on furan ring. The ${ }^{1} \mathrm{H}-\mathrm{NMR}$ spectrum also showed signals in the oxygenated and nonoxygenated aliphatic carbon. The ${ }^{13 \mathrm{C}-\mathrm{NMR}}$ spectrum of compound 2 with the help of DEPT135 revealed the presence of 35 carbon resonances of which three methylene's, 13 methine, 8 methyl and the remaining 11 carbons are quaternary. The signal due to carbonyl compound of a ketone was observed at 204.5. The presences of five ester carbonyls are evident at 173.5, 170.7, 169.7, 168.6 and 166.6. Also observed in the aromatic region are signals due the furan ring at 143.0, 141.2, 120.3 and 109.9. The signals due to olefinic carbon were observed at 139.6 and 116.6. The spectrum also showed signals in the oxygenated and nonoxygenated aliphatic carbons. The data regenerated agreed well with the compound whose structure is drawn in (Fig. 2).
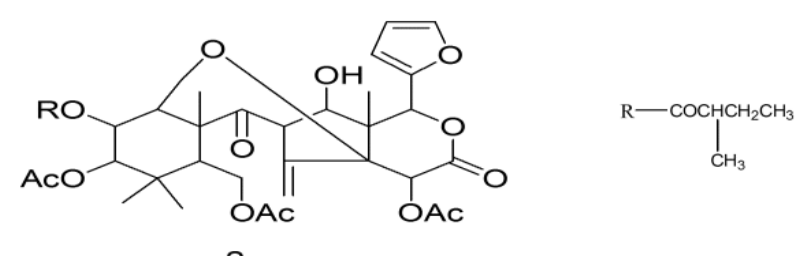

Fig. 2: Chemical structure of compound 2 (Sandropin B).

\section{Discussion}

\section{Antimicrobials effect of crude extracts}

This study indicated that considerable difference in antimicrobial activity between extracts obtained with different solvents. Ethyl acetate extracts were the most active extract against the Gram-positive bacteria (S. aureus) and the fungi (C. albicans). No activity was observed by the crude extract against Gram-negative bacteria ( $P$. aeruginosa). The reason for the difference in activity against Gram positive and Gram negative bacteria possibly lies in their morphological differences. However, the detail mechanism of action of the extract should be further investigated.

This study provided evidence that ethyl acetate extract of E. capensis possesses significant antibacterial (multi-drug resistance $S$. aureus) and antifungal activities on $C$. albicans. This activity may be due to the major components for $E$. capensis which include cinnamaldehyde and terpenoids (Budri et al., 2015). Similar results were obtained by Keskin and Toroglu (2011), and these results were also compatible with the result obtained by Utchariyakiat et al., (2016), where they showed a strong antibacterial activity of $C$. zeylanicum against $S$. aureus. In addition, the results obtained in this study agreed with the result obtained by Krishnan and Nair (2016), which showed that the extract of $C$. zeylanicum had higher inhibitory effect against $S$. aureus. In relation to antifungal activity against $C$. albicans, a study by Castro and Lima (2013), showed MIC values ranging between 0.3 and $0.6 \mathrm{mg} / \mathrm{ml}$ significantly lower than this current finding (10 $\mathrm{mg} / \mathrm{ml}$ ).

A study by Alrumman (2015) showed that $T$. aphylla leaves possessed a significant antimicrobial activity against the human pathogens $S$. aureus, Klebsiella pneumoniae, $K$. oxytoca, Proteus mirabilis, $P$. aeruginosa, Micrococcus luteus, Shigella sp., and Candida sp. This is in full agreement with our result against $S$. aureus and C.albicans. The result obtained by Zarai et al. (2011) indicated the absence of inhibition zones and no planktonic growth inhibition activity (MIC) against $P$. aeruginosa for $M$. vulgare crude extract. This might be due to the insufficient concentration of the extract or due to absence of bioactive compound against the test organisms. However, several recent investigators reported antimicrobial (Bereksi et al., 2018; Tamfu et al, 2020) and antifungal (Tang et al., 2019) activities of various plant extracts which indicate the prospect of plant natural products for human pathogen control.

The bioactivity results were considered evidence of the presence of more compounds in the crude extract of ethyl acetate, compared to the methanol and hexane extracts of Ekebergia capensis. The 
possible reason for this might be due to the slight polarity of the compounds in the bark of $E$. capensis. The slightly polar compounds were more soluble in ethyl acetate as compared to methanol and hexane. However, different activities against $S$. aureus, $P$. aeruginosa, $C$. albicans were observed by fractionated compounds. The inhibition activity at different concentration showed different zone of inhibition by purified compounds from ethyl acetate extract of E. capensis. This purified compound from ethyl acetate extract of $E$. capensis used in this study showed variable antibacterial activities against $P$. aeruginosa at concentrations ranging from 10 to $5 \mathrm{mg} / \mathrm{ml}$.

\section{In vitro effect of plant crude extracts on biofilm formation}

The present study focused on the anti-biofilms and QS inhibitory effect of medicinal plant extracts. The activity of the extracts on inhibition of biofilm formation was tested using the crystal violet (CV) method, which is widely used by microbiologists. It is inexpensive and can be repeated many times to ensure accurate results (reproducible). The extracts used in this, showed antibacterial activity against $S$. aureus and $P$. aeruginosa at 10 and $5 \mathrm{mg} / \mathrm{ml}$ concentration. The reason for the selection of $S$. aureus and $P$. aeruginosa in this assay is the fact that the biofilms forming ability of this bacterium contribute to its colonization in causing acute infections as well as its presence in burned tissue surrounding blood vessels and adipose cells (Schaber et al., 2007). Various results were obtained on inhibition of biofilm for E. capensis, $C$. edulis and $P$. resinosa extracts. E. capensis showed prominent antimicrobial and anti-biofilm activities. In this study, the E. capensis extracts tested prevented the formation of biofilm at concentration of $10 \mathrm{mg} / \mathrm{mL}$, like a study by Pratiwi (2015), which prevented the formation of biofilm at concentration of $9 \mathrm{mg} / \mathrm{ml}$. A low concentration of the extract may be required to prevent biofilm first attachment, while higher concentration to disrupt preformed biofilm (Stewart, 2002). This study indicated the potential E. capensis plant extract for antibacterial and/or anti-biofilm activity, thau, may prove helpful for developing biofilm inhibitors and increase the effectiveness of infectious diseases treatment. E. capensis showed remarkable potential as anti-biofilm agent, as it was active upon $P$. aeruginosa, $S$. aureus, $C$. albicans in the planktonic state. Thus far, no articles on antibiofilm activity of extract of E. capensis was published, however it failed to reduce the QS in most assays. E. capensis extract showed strong anti-biofilm activity against $S$. aureus and $P$. aeruginosa compared to the untreated control. These medicinal plants could be used to manage Pseudomonas pathogenesis and hinder its dissemination. To the best of our knowledge, no reports are available regarding the anti-biofilm activity $E$. capensis extract against $S$. aureus $P$. aeruginosa and $C$. albicans. The anti-QS potential of plant extracts to explore the potential to a possible use in controlling detrimental pathogenic bacteria such as: $S$. aureus $P$. aeruginosa. This results in different system/pathway of quorum sensing by $S$. aureus $P$. aeruginosa and $C$. albicans.

We investigated the potential of the extracts which inhibited $S$. aureus, $P$. aeruginosa and $C$. albicans motility as a mean for determining the inhibition of quorum sensing as an alternative strategy for controlling bacterial virulence as suggested by Vasavi et al. (2014). The swarming motility is important for cystic fibrosis acute infections, common cause of severe nosocomial infections, and involved at early stages of biofilm formation. Three major forms of motility are displayed by $S$. aureus and $P$. aeruginosa (swarming on semisolid, on solid surfaces, and flagellum-mediated swimming in aqueous environments). The swarming assay depends on factors such as nutrient composition, agar type and composition, sterilization protocol (e.g., autoclaving), and semisolid media curing among others. Thus, it is highly sensitive to environmental factors. The edge of the colonies in smarming motility is highly irregular compared with control. Flagellar-mediated swimming motility is associated with biofilm formation by instigating the cell-to-surface attachment and plays an important role in the virulence of pathogens (Wu et al., 2014).

E. capensis extract reduced the swarming motility of $S$. aureus and $P$. aeruginosa. It might be because of phytochemicals of $E$. capensis on flagella-related processes, namely, flagella biosynthesis, rotation, rafting and chemotaxis, etc. Interestingly, Tremblay and Deziel (2008) reported that swarming motility assays of $P$. aeruginosa are influenced by incubation temperature, percentage of agar, $\mathrm{pH}$, and drying 
time under laminar flow. In this study, we used molten soft top agar for all experiments about swarming motility. Interestingly, studies associated with some natural products have shown that plant extracts with poor antimicrobial properties could also be effective against bacterial biofilms (Upadhyay, 2014; Zhang et al., 2014).

\section{Conclusion}

The finding of this present study demonstrated the potential of extracts and isolated bioactive compounds from E. capensis for antimicrobials, anti-biofilm and anti-quorum sensing activity. Ethyl acetate extract of E. capensis showed antimicrobial activities against $C$. albicans and $S$. aureus, inhibited biofilm formation of $S$. aureus and $P$. aeruginosa, exhibited inhibition of swarming motility against $P$. aeruginosa, $S$ aureus and $C$. albicans. Two compounds, BEE-28 $\mathrm{C}_{16} \mathrm{H}_{22} \mathrm{O}_{4}$ (diisobutylphtalate) and BEE-32 $\mathrm{C}_{35}$ $\mathrm{H}_{42} \mathrm{O}_{14}$, (Sandropin B) were elucidated from bark $E$. capensis using ethyl acetate as extraction solvent. Ethyl acetate extract of $E$. capensis constitutes an interesting source for anti-biofilm agents in the development of new strategies to treat infections. The result represents a call for examining the possibility of using $E$. capensis or its components in ethnomedicine and drug discovery from natural sources.

\section{Conflict of interest statement}

Authors declare that they have no conflict of interest.

\section{References}

Alrumman, S., 2015. Phytochemical and antimicrobial properties of Tamarix aphylla $L$. leaves growing naturally in the Abha region, Saudi Arabia. Arabian J. Sci. Eng. 3, 1-7.

Bereksi, M. S., Hassaïne, H., Bekhechi, C., Abdelouahid, D. E., 2018. Evaluation of antibacterial activity of some medicinal plants extracts commonly used in Algerian traditional medicine against some pathogenic bacteria. Pharmacog. J. 10(3), 507-512.

Budri, P., Silva, N., Bonsaglia, E., Fernandes, A., Araujo, J., Doyama, J., Rall, V., 2015. Effect of essential oils of Syzygium aromaticum and Cinnamomum zeylanicum and their major components on biofilm production in Staphylococcus aureus strains isolated from milk of cows with mastitis. J. Dairy Sci. 98, 5899-5904.

Berlanga, M., Guerrero, R., 2016. Living together in biofilms: the microbial cell factory and its biotechnological implications. Microbial Cell Factories 15, 165.

Castro, R., Lima, E., 2013. Anti-candida activity and chemical composition of Cinnamomum zeylanicum Blume essential oil. Brazilian Arch. Biol. Technol. 56, 749-755.

Clutterbuck, A., Cochrane, C., Dolman, J., Percival, S., 2007. Evaluating antibiotics for use in medicine using a poloxamer biofilm model. Ann. Clin. Microbiol. Antimicrob. 6, 476.

Keskin, D., Toroglu, S., 2011. Studies on antimicrobial activities of solvent extracts of different spices. Journal of Environmental Biology 32(2): 251-256.

Koh, Ch., Sam, Ch., Yin, W., Tan, L., Krishnan, T., Chong, Y., Chan, K., 2013. Plant-derived natural products as sources of anti-quorum sensing compounds. Sensors 13, 6217-6228.

Krishnan, T., Yin, W., Chan, G., 2012. Inhibition of quorum sensing-controlled virulence factorproduction in Pseudomonas aeruginosa PAo1 by ayurveda spice clove (Syzygium aromaticum) bud extract. Sensors 12, 40164030.

Ling, L., Schneider, T., Peoples, J., Spoering, A., Conlon, B., Mueller, A., Lewis, K., 2015. A new antibiotic kills pathogen without detectable resistance. Nature 17, 455-459.

Mishra, S., Yang, X., Ray, S., Fernandes, LF., Singh, H. B., 2020. Antibacterial and biofilm inhibition activity of biofabricated silver nanoparticles against Xanthomonas oryzae pv. oryzae causing blight disease of rice instigates disease suppression. World $\mathrm{J}$. Microbiol. Biotechnol. 36, 55.

Liu, Q., Shen, Y., Yin, K., 2020. The antimicrobial activity of protein elicitor AMEP412 against Streptomyces scabiei. World J. Microbiol. Biotechnol. 36, 18.

Ncube, N., Afolayan, A., Okoh, A., 2008. Assessment techniques of antimicrobial properties of natural compounds of plant origin: current methods and future trends. Afr. J. Biotechnol. 7, 1797-1806.

Pratiwi, S., 2015. Anti-microbial and anti-biofilm compounds from Indonesian medicinal plants. 
Institute Biology Leiden (IBL), Faculty of Science, Leiden University.

Schaber, J., Triffo, W., Suh, S., Oliver, J., Hastert, M., Griswold, A., Rumbaugh, K., 2007. Pseudomonas aeruginosa forms biofilms in acute infection independent of cell-to-cell signalling. Inf. Immun. 75, 3715-3721.

Stewart, P., 2002. Mechanisms of antibiotic resistance in bacterial biofilms. Int. J. Med. Microbiol. 2, 107-113.

Tang, L., Mo, J., Guo, T., Huang, S., Li, Q., Ning, P., Hsiang, T., 2019. In vitro antifungal activity of dimethyl trisulfide against Colletotrichum gloeosporioides from mango. World J. Microbiol. Biotechnol. 36, 4.

Tamfu, A. N., Ceylan, O., Fru, GC., Ozturk, M., Duru, ME., Shaheen, F., 2020. Antibiofilm, antiquorum sensing and antioxidant activity of secondary metabolites from seeds of Annona senegalensis, Persoon, Microb. Pathogen. 144, 104191.

Tanver, A., Peng, M., Hongxin, G., 2017. Antiquorum sensing and anti-biofilm activity of Amomum tsaoko on foodborne pathogens. Saud. J. Biol. Sci. 24, 3-12.

Tremblay, J., Deziel, E., 2008. Improving the reproducibility of Pseudomonas aeruginosa swarming motility assays. J. Basic Microbiol. 48, 509-515.

Upadhyay, A., 2014. Investigating the potential of plant-derived antimicrobials and probiotic bacteria for controlling Listeria monocytogenes (Doctoral Dissertations). Paper 326.

Utchariyakiat, I., Surassmo, S., Jaturanpinyo, M., Khuntayaporn, P., Chomnawang, M., 2016. Efficacy of cinnamon bark oil and cinnamaldehyde on anti-multidrug resistant Pseudomonas aeruginosa and the synergistic effects in combination with other antimicrobial agents. BMC Compl. Alt. Med. $16,158$.

Vasavi, H., Arun, B., Rekha, D., 2014. Anti-quorum sensing activity of Psidium guajava $L$. flavonoids against Chromobacterium violaceum and Pseudomonas aeruginosa PAO1. Microbiol. Immunol. 5, 286-293.

Wu, H., Moser, C., Wang, Z., Hoiby, N., Song, J., 2014. Strategies for combating bacterial biofilm infections. Int. J. Oral Sci. 7, 1-7.

Zarai, Z., Kadri, A., Chobba, I., Mansour, B., Bekir, A., Mejdoub, H., Gharsallah, N., 2011. The invitro evaluation of antibacterial, antifungal and cytotoxic properties of Marrubium vulgare L. essential oil grown in Tunisia. Lipids Health Dis. 10, 1-9

Zhang, J., Rui, X., Wanga, L., Guana, Y., Sunc, X., Dong, M., 2014. Polyphenolic extract from Rosa rugosa tea inhibits bacterial quorum sensing and biofilm formation. Food Control 42, 125131.

\section{How to cite this article:}

Meka, A. F., Ayana, Y. M., Biru, T. G., 2020. Antimicrobial, anti-biofilm and anti-quorum sensing compounds from the bark of Ekebergia capensis. Int. J. Curr. Res. Biosci. Plant Biol. 7(9), 20-28.

doi: https://doi.org/10.20546/ijcrbp.2020.709.003 